\author{
${ }^{1}$ N. Ghasempour iD, ${ }^{1}$ A.H. Elhami Rad ${ }^{(D)},{ }^{2 *}$ M. Javanmard, \\ ${ }^{3}$ E. Azarpazhouh ${ }^{\text {ID }, ~}{ }^{1}$ M.Armin ${ }^{\text {i }}$ \\ ${ }^{1}$ Department of Food Science and Technology, Islamic Azad University, Sabzevar, Iran \\ ${ }^{2}$ Food technologies group, Chemical Engineering Institute, \\ Iranian Research Organization for Science and Technology (IROST), Tehran, Iran \\ ${ }^{3}$ Agricultural Engineering Research Department, Khorasan Razavi Agricultural and \\ Natural Resources Research and Education Center, AREEO, Mashhad, Iran \\ *e-mail: javanmard@irost.ir

\section{Optimization of conditions of ultrasound-assisted extraction of phenolic compounds from orange pomace (Citrus sinensis)}

\begin{abstract}
Every year millions of tons of fruit peels, such as that from apples, oranges and pomegranates are disposed of as juice factory wastes in our country as well as globally. As we know today special attention is given to the optimum use of plant wastes and extraction of bioactive compounds, namely, antioxidants and antimicrobials. Unfortunately, Iran with a 15.2-30\% green waste production, currently holds the first place in the world fruit waste production. The current study was carried out with the goal of optimizing the ultrasound-assisted extraction of antioxidant compounds from orange pomace. In this optimization by use of the response surface method, a Box-Behnken design was evaluated for three variables consisting of ultrasonication amplitude (20,60 and 100\%), ultrasonication time (15, 35 and $55 \mathrm{~min})$ and ultrasonication temperature $\left(35,50\right.$ and $\left.65^{\circ} \mathrm{C}\right)$. The results showed if the extraction time, extraction temperature and ultrasonication Amplitude were to be set at $26.43 \mathrm{~min}, 35^{\circ} \mathrm{C}$ and $65.66 \%$, respectively, the highest antimicrobial antioxidant compound extraction efficiency would be reached. Under such conditions, phenolic compounds amount of $91.96 \mathrm{mg}$ of gallic acid, free radical inhibition of $57.89 \%$ and extraction efficiency of $10.62 \%$ were attained. The results demonstrated that ultrasonication could be a very effective method for continuous extraction of antioxidant compounds from fruit waste.
\end{abstract}

Key words: antioxidant, Box-Behnken design, orange pomace extract, total phenolic compound, ultrasound.

\section{Introduction}

Every year millions of tons of fruit peels, such as that from apples, oranges and pomegranates are disposed of as juice factory wastes in our country as well as globally. As we know it today special attention is given to the optimum use of plant wastes and extraction of biologically active compounds, namely, antioxidants and antimicrobials [1]. Unfortunately, Iran with a $15.2-30 \%$ green waste production, currently holds the first place in the world fruit waste production. On the one hand, wastes lead to loss of national resources, on the other hand, the disposal of which causes some difficulties. For example, wastes rich in phenolic compounds, which are usually buried in the ground, in addition to being expensive, cause environmental problems [2].
From another point of view, the pursuit of finding replacements for synthetic antioxidants has led to examination of numerous antioxidants from plant sources. Examinations have shown that antioxidant activity of some fruits and vegetables is dependent on the total amounts of phenolic compounds in them. Taking the fact that plants are natural sources of antioxidants, research in this field is increasing. Citrus fruits possess considerable antioxidant activity, containing large numbers of flavonoids. Recent research has been to explore ways of natural development of these compounds; it has been established that the antioxidant amount varies in different numbers and structures.

Choice of the extraction method is one of the main factors, which can affect the properties of the effective constituents of extracts [3]. Usually, extraction by conventional methods requires a long pe- 
riod of time, high temperature and solvent amount. Thermal extraction causes antioxidant degradation and reduces the antioxidant activity of the produced extract. There are different extraction methods from plants and fruits $[1 ; 3 ; 4]$. The use of novel and practical methods, such as the ultrasound process for extraction of higher quality, more stable, soluble in water and remaining safe extracts along with reduced related expenses (high efficiency and low energy and water consumption), seems important [5-7]. Ultrasound-assisted extraction, can lead to higher extraction of effective constituents from orange pomace. More than 88000000 tons of various citrus fruits are produced worldwide each year, of which wastes account for about 15000000 tons. Citrus wastes usually consist of water, soluble sugars, fiber, organic acids, amino acids, protein and minerals of different amounts. Considering the vast amounts of protein and fibers present in citrus wastes they can be used as a high-energy source in livestock diet.

In recent years, various researches have been carried out in the field of application of ultrasound waves in processing of food materials. For instance, Sharayei et al. performed a study with the purpose of optimum use of pomegranate peel as the residue of agriculture and pomegranate juice factories, and extraction of biologically active compounds (antioxidant and antimicrobial), employing the ultrasound-assisted method. Results showed that all aqueous extracts of pomegranate and peel, possessed the antioxidant activity and antioxidant potency of $6 \%$ aqueous extract of pomegranate peel, was roughly the same as that of synthetic butylated hydroxytoluene antioxidants [8]. A study was carried out on the effects of high-powered ultrasound waves on ground olive grains. It was determined that in the presence of these waves, cell walls and plant tissues are disrupted and more antioxidant compounds (polyphenols and tocopherols) and pigments (chlorophyll and carotenoid) found a way into the oil and led to an increase in nutrition rating [9]. Rosangela et al. examined the chemical composition of yerba mate tea (Ilex paraguariensis leaves) using the ultrasound-assisted method. The use of ultrasound waves led to improved caffeine and palmitic acid amounts efficiencies in methanol solvent [12]. In this study, optimization of ultrasoundassisted extraction of phenolic compounds from orange pomace, and later comparison between the two methods, i.e., maceration and ultrasonication are under the scope.

\section{Materials and methods}

Plant materials. Orange wastes were purchased from Iran Citrus Co. (Tonekabon, Mazandaran Province) in August, 2016. The wastes, after drying at room temperature and away from sunlight, were completely dried and grounded using an electric grinder and passed through a mesh strainer No. 20 and kept at a dark, cold and dry place.

Chemicals and reagents. All chemicals and reagents used in this study, were analytical grade, including Folin-Ciocalteu reagent (FC), gallic acid, DPPH (2,2-diphenyl-1-picrylhydrazyl) reagent obtained from Sigma-Aldrich Corp. (St. Louis, MO), chemical and organic solvents purchased from Merck KGaA (Darmstadt, Germany).

Extraction procedures. In order to produce extracts from orange wastes, the maceration and ultrasound-assisted methods were used. The solvent used in both methods was $70 \%$ ethanol.

Maceration extraction method. For this purpose, $100 \mathrm{~g}$ of powdered orange pomace was carefully weighed and poured into a $1000 \mathrm{~mL}$ beaker containing $70 \%$ ethanol solvent and stirred for $24 \mathrm{~h}$ at room temperature. The solution was then filtered under vacuum and concentrated up to the point of full dewatering using a rotary dryer (Laborota 4000, Germany) at $45^{\circ} \mathrm{C}$ in an oven until reaching constant weight under vacuum.

Ultrasound-assisted extraction method. For this purpose, a $100 \mathrm{~g}$ of powdered orange pomace was carefully weighed and poured into a $1000 \mathrm{~mL}$ beaker containing $70 \%$ ethanol solvent and moved to the special ultrasonication chamber. For ultrasonication, the ultrasonic device model (UP400S, Heilscher, Germany) with $400 \mathrm{~W}$ power and $\mathrm{H} 7$ type probe made from titanium; diameter $-7 \mathrm{~mm}$, length -100 $\mathrm{mm}$ was used. For extraction, parameters of ultrasonication changed as follows: time $-15,35$ and 55 min, amplitude $-20,60$ and $100 \%$, temperature -35 , 50 and $65^{\circ} \mathrm{C}$; with the sound frequency of $24 \mathrm{kHz}$ based on the variables surfaces predicted in the BoxBehnken design, according to Table 1, were selected.

Statistical analysis. In order to study the effect of time, temperature and amplitude of the process on optimization of extraction conditions of phenolics, tests were performed based on an RSM design in 3 factors and 3 design surfaces and a Box-Behnken design. The software in use was Design Expert and graphs were drawn by Microsoft Excel. The coded and actual levels of each of the variables are given in Table 2. 
Table 1 - Random treatments of the Box-Behnken design experimentation

\begin{tabular}{|c|c|c|c|}
\hline Treatment & Time $(\min )(\mathrm{A})$ & Temperature $\left({ }^{\circ} \mathrm{C}\right)(\mathrm{B})$ & Amplitude $(\%)(\mathrm{C})$ \\
\hline 1 & 55 & 65 & 60 \\
\hline 2 & 55 & 65 & 20 \\
\hline 3 & 35 & 65 & 60 \\
\hline 4 & 15 & 65 & 20 \\
\hline 5 & 35 & 50 & 100 \\
\hline 6 & 15 & 50 & 60 \\
\hline 7 & 55 & 35 & 60 \\
\hline 8 & 15 & 50 & 20 \\
\hline 9 & 35 & 50 & 100 \\
\hline 10 & 55 & 35 & 20 \\
\hline 11 & 35 & 35 & 100 \\
\hline 12 & 35 & 50 & 60 \\
\hline 13 & 15 & 50 & 60 \\
\hline 14 & 35 & 50 & \\
\hline 15 & 35 & & 60 \\
\hline
\end{tabular}

Table 2 - Valuable codes, independence variables and actual value used in ultrasound method

\begin{tabular}{|c|c|c|}
\hline Independence variables & Valuable codes & Actual value \\
\hline Time & $-1,0,+1$ & $15,35,55$ \\
\hline Temperature & $-1,0,+1$ & $35,50,65$ \\
\hline Amplitude & $-1,0,+1$ & $20,60,100$ \\
\hline
\end{tabular}

Measurement of TPC. The total phenolic content (TPC) in the extract produced from the two extraction methods, maceration and ultrasonication, was determined with Folin-Ciocalteu [11]. For that $500 \mu \mathrm{L}$ of the extract solution were poured into a test tube and then $500 \mu \mathrm{L}$ of the diluted Folin-Ciocalteu solution with a 1:10 ration and 6 c.c. of distilled water were added to the solution. 8 minutes later, $1.5 \mathrm{~mL}$ of $20 \%$ sodium carbonate were added and adequately stirred. The compound within the test tube was incubated for $30 \mathrm{~min}$ at room temperature and the absorbency read at $765 \mathrm{~nm}$ on the spectrophotometer with the following formula (Eq.1).

$$
\mathrm{P}=\frac{Y}{W} * 1000
$$

where

$$
\begin{aligned}
& \mathrm{P} \text { - TPC (mg gallic acid per } \mathrm{g}) \\
& \mathrm{Y} \text { - TPC (mg gallic acid per } \mathrm{mL}) \\
& \mathrm{W} \text { - sample weight }(\mathrm{g})
\end{aligned}
$$

The total phenolic content from the drawn linear equation based on gallic acid $(0,30,70,110,150$, Int. j. biol. chem. (Online)
190 and $200 \mathrm{ppm}$ in $70 \%$ ethanol), was expressed as $\mathrm{mg}$ of gallic acid per $\mathrm{g}$ of dried extract.

Estimation of antioxidant capacity. Estimation of the free radical-scavenging activity was performed through the use of the DPPH test and 2,2-diphenyl picrylhydrazyl reagent [12]. The DPPH reagent was obtained by adding $0.009 \mathrm{~g}$ of 2,2-diphenyl picrylhydrazyl reagent to $75 \mathrm{~mL}$ of methanol. A $\mathrm{ml}$ of the aforementioned solution was added to the $500 \mu \mathrm{L}$ sample and then $3.5 \mathrm{~mL}$ of methanol was added to it. Then stirring was carried out for $30 \mathrm{~s}$. The solution produced was incubated at room temperature for 90 min and the absorbency of the sample reported at 512 nanometers on the spectrophotometer device in the following formula (Eq.2).

$$
\text { DPPH }(\%)=\frac{A \text { count }-A \text { sample }}{A \text { count }} * 100,
$$

where

$$
\begin{aligned}
& A_{\text {count }}-\text { Absorbance of control } \\
& A_{\text {sample }}-\text { Absorbance of sample }
\end{aligned}
$$

International Journal of Biology and Chemistry 12, № 2, 10 (2019) 
Extraction yield. The extraction efficiency is given by the following formula (Eq. 3):

$$
\mathrm{EY}=\frac{\text { Dried extraction weight }}{\text { inital sample weight }} * 100
$$

\section{Results and discussion}

Model fitting. After data analysis with the goal of finding the best-suggested model from the five existing: mean, cubic, 2FI, linear, variance analysis, for which the sum of squares had significant differences, and the lack of fit was insignificant, the best model was selected. Given this subject and after examining the results obtained and a comparison between the existing regression models, the results indicated that the Quadratic model for TPC, DPPH free radical-scavenging capacity and measured extraction efficiency tests in this study, had a significant difference compared to the other models. There models for which the Lack of fit was undefined (Table 3). Consequently, the Quadratic model was selected for examining the trend of variations of the parameters measured in this study. After selecting the best model in the desired statistical surface $(1 \%$ or $5 \%)$, in order to examine the effective parameters in the study, with regard to the variance table, the parameter for which the $\mathrm{F}$ test insignificant $(\mathrm{P}>0.05)$, is eliminated and the rest of parameters which had significant differences were kept.

It is worth mentioning that in the case that the linear parameter of a variable in a model, does not have a significant effect, yet its mutual effect with one of the other variables, which has a significant effect in the model, does have a significant effect, then that parameter is kept in the model and afterward the general equation is derived for any parameter, by the given coefficients. Ultimately, from amongst the different parameters, the parameter which has the highest sum of squares is selected as the most effective parameter.

Table 3 - Analysis of variance of the regression coefficients of the obtained models over the response variables (quantitative and qualitative properties) of orange pomace extract

\begin{tabular}{|c|c|c|c|c|c|c|c|}
\hline \multirow[t]{2}{*}{ Source } & \multirow[t]{2}{*}{$\mathrm{df}$} & \multicolumn{2}{|c|}{ EY (\%) } & \multicolumn{2}{|c|}{ TPC (mg GA/100 g) } & \multicolumn{2}{|c|}{ DPPH (\%) } \\
\hline & & Coefficient & $\begin{array}{l}\text { Sum of } \\
\text { Squares }\end{array}$ & Coefficient & $\begin{array}{l}\text { Sum of } \\
\text { Squares }\end{array}$ & Coefficient & $\begin{array}{l}\text { Sum of } \\
\text { Squares }\end{array}$ \\
\hline Model & 9 & $3.56^{*}$ & 48.97 & $-183.29^{*}$ & 9911.71 & $36.93^{* *}$ & 1732.43 \\
\hline \multicolumn{8}{|l|}{ Linear } \\
\hline Time (A) & 1 & $0.09^{*}$ & 7.26 & $0.025^{*}$ & 3257.05 & $-0.097^{\mathrm{ns}}$ & 0.0015 \\
\hline Temperature (B) & 1 & $0.01^{\mathrm{ns}}$ & 0.80 & $7.87^{\mathrm{ns}}$ & 904.83 & $0.366^{*}$ & 208.28 \\
\hline Amplitude (C) & 1 & $0.19^{*}$ & 12.70 & $3.28^{*}$ & 1371.83 & $0.774^{* *}$ & 633.86 \\
\hline \multicolumn{8}{|l|}{ Quadratic } \\
\hline $\mathrm{A} * \mathrm{~A}$ & 1 & ns -0.0029 & 5.14 & $-0.0084^{\mathrm{ns}}$ & 41.87 & $-0.019^{*}$ & 228.91 \\
\hline$B * B$ & 1 & $-0.0004^{\mathrm{ns}}$ & 0.044 & $-0.064^{\mathrm{ns}}$ & 780.33 & $-0.0087^{\mathrm{ns}}$ & 14.42 \\
\hline $\mathrm{C}^{*} \mathrm{C}$ & 1 & $-0.0013^{* *}$ & 18.12 & $-0.016^{*}$ & 2639.61 & $-0.0021^{\mathrm{ns}}$ & 44.04 \\
\hline \multicolumn{8}{|l|}{ Interaction } \\
\hline$A * B$ & 1 & $0.002^{\text {ns }}$ & 2.82 & $-0.018^{\mathrm{ns}}$ & 121.88 & $0.029^{* *}$ & 320.77 \\
\hline$A^{*} \mathrm{C}$ & 1 & $0.00036^{\text {ns }}$ & 0.34 & $0.0079^{\mathrm{ns}}$ & 160.53 & $-0.0002^{\text {ns }}$ & 0.198 \\
\hline $\mathrm{B}^{*} \mathrm{C}$ & 1 & $-0.0014^{\mathrm{ns}}$ & 3.06 & $-0.024^{\mathrm{ns}}$ & 876.75 & $-0.014^{* *}$ & 305.20 \\
\hline Residuals & 5 & & 4.84 & & 195.15 & & 82.71 \\
\hline Lack of Fit & 3 & & 0.95 & & 128.66 & & 14.76 \\
\hline Pure Error & 2 & & 3.88 & & 66.49 & & 67.95 \\
\hline Total & 14 & & 53.80 & & 12077.7 & & 1815.14 \\
\hline Std. Dev & & 0.98 & & 15.04 & & 4.07 & \\
\hline Mean & & 8.93 & & 63.37 & & 45.36 & \\
\hline $\mathrm{CV}(\%)$ & & 11.02 & & 23.73 & & 8.97 & \\
\hline $\mathrm{R}^{2}$ & & 0.91 & & 0.89 & & 0.95 & \\
\hline Adj $R^{2}$ & & 0.74 & & 0.71 & & 0.87 & \\
\hline
\end{tabular}

Note: ${ }^{\text {ns }}$ - no significant effect at level $>0.1$; Std. Dev (standard deviation) $-{ }^{*} \mathrm{P}<0.05 ;{ }^{* *} \mathrm{P}<0.01 ;{ }^{* * *} \mathrm{P}<0.001$ 
Investigating the effect of independent variables on qualitative and quantitative properties of orange pomace: effects of process variables on TPC extraction. The results from the variance analysis of the extract, extracted from orange pomace, quantitative and qualitative - experimental and predicted properties produced from the central combined design in the orange pomace extract production process, are given in Table 4.

With regard to Equation. 4 and Table 3, the parameters $\mathrm{A}$ and $\mathrm{C}^{2}$ were selected as the most effective factors in the extraction of phenolic compounds, using Eq.4.

$$
\begin{gathered}
\mathrm{TPC}=-183.29+0.025 \mathrm{~A}+7.87 \mathrm{~B}+3.28 \mathrm{C}- \\
0.018 \mathrm{AB}+0.0079 \mathrm{AC}-0.024 \mathrm{BC}-0.0084 \mathrm{~A}^{2}-0.064 \mathrm{~B}^{2}- \\
0.016 \mathrm{C}^{2}
\end{gathered}
$$

In the RSM methodology, there is a step called Verification. In this step, the value for total phenolic compounds extraction in the extermination step should be statistically compared to the value predicted by the model. In this examination, after having carried out this step, the observed values were compared to the predicted values and the calculations may be seen in Table 4; the results are demonstrative of the good correlation between results obtained from the experimental method and the values predicted with the statistical method.

The significance of the quadratic temperature term shows that the rising trend of the amount of phenolics extraction continues until around $49{ }^{\circ} \mathrm{C}$ and declines with further increase in temperature (Figure 1-A). This phenomenon which has been reported in various studies is probably due to the destruction and oxidization of some of the heatsensitive polyphenols at higher temperatures [13; 14]. Additionally, the rise of temperature also expands the level of phenolic compounds extraction and because of the increase in solubility of phenolics, the rate of mass and heat transfer occurs faster [15].

Table 4 - Dependent and independent variables

\begin{tabular}{|c|c|c|c|c|c|c|c|c|}
\hline \multirow{2}{*}{ Time (min) } & \multirow{2}{*}{ Temp. $\left({ }^{\circ} \mathrm{C}\right)$} & \multirow{2}{*}{$\begin{array}{c}\text { Amplitude } \\
(\%)\end{array}$} & \multicolumn{2}{|c|}{ EY (\%) } & \multicolumn{2}{|c|}{ TPC (mg GA/100 gr) } & \multicolumn{2}{c|}{ DPPH (\%) } \\
\cline { 5 - 10 } & & Real Values & $\begin{array}{c}\text { Predicted } \\
\text { Values }\end{array}$ & Real Values & $\begin{array}{c}\text { Predicted } \\
\text { Values }\end{array}$ & Real Values & $\begin{array}{c}\text { Predicted } \\
\text { Values }\end{array}$ \\
\hline 55 & 35 & 60 & 10.14 & 9.94 & 60 & 65.25 & 38.03 & 38.77 \\
\hline 55 & 65 & 60 & 11.4 & 10.99 & 26.49 & 32.94 & 44.81 & 46.48 \\
\hline 35 & 65 & 20 & 10.3 & 10.29 & 30.08 & 36.98 & 59.6 & 59.56 \\
\hline 15 & 65 & 60 & 7.2 & 7.40 & 89.59 & 84.34 & 29.28 & 28.54 \\
\hline 35 & 65 & 100 & 5.8 & 6.02 & 41.66 & 33.56 & 25.18 & 24.29 \\
\hline 15 & 50 & 20 & 8.2 & 8.01 & 72.14 & 70.49 & 49.02 & 49.80 \\
\hline 55 & 50 & 100 & 7.2 & 7.39 & 54.68 & 56.33 & 32.8 & 32.02 \\
\hline 15 & 35 & 60 & 9.3 & 9.72 & 101.02 & 94.57 & 58.32 & 56.65 \\
\hline 35 & 50 & 60 & 9.65 & 10.80 & 71.15 & 87.18 & 46.51 & 52.46 \\
\hline 55 & 50 & 20 & 8.9 & 9.32 & 30.82 & 17.47 & 51.9 & 50.27 \\
\hline 35 & 35 & 100 & 8.4 & 8.41 & 91.34 & 84.44 & 51.93 & 51.97 \\
\hline 35 & 35 & 20 & 9.4 & 9.18 & 20.54 & 28.64 & 51.41 & 52.30 \\
\hline 15 & 50 & 100 & 5.32 & 4.90 & 70.66 & 84.01 & 30.81 & 32.44 \\
\hline 35 & 50 & 60 & 12.35 & 10.80 & 98.25 & 87.18 & 52.71 & 52.46 \\
\hline 35 & 50 & 60 & 10.4 & 10.80 & 92.14 & 87.18 & 58.16 & 52.46 \\
\hline
\end{tabular}

Results acquired from the Ahmadian and Niazmand study illustrate the specific effect of the mean temperature $\left(43{ }^{\circ} \mathrm{C}\right)$ on the extraction of polyphenolic compounds from the saffron petal [16]. The effect of temperature on increasing extraction efficiency is

Int. j. biol. chem. (Online) most probably due to the improvement of mass transfer at a higher temperature and therefore increasing the solubility of phenolic compounds, increasing the penetration rate and decreasing the coefficient of viscosity, of the solvent. In addition, the rise in extrac- 
tion temperature, bringing about the dissociation of the bonds of the phenolic compounds with the rest of the compounds and affecting the membrane structure of plant cells can be responsible for extraction procedure facilitation.

As apparent from Figure 1-B, by increasing the time from 15 to $25 \mathrm{~min}$, the extraction efficiency amount increases. The underlying reason for these results may be explained in such a way that a prolonged contact time (the extraction time) leads to oxidization of phenolic compounds due to light or oxygen expression [17].

According to the investigation carried out in the research on ultrasound-assisted extraction of phenolic compounds from wheat bran, the extraction amount of these compounds markedly increased from 15 to $30 \mathrm{~min}$ but then roughly decreased from 30 to $50 \mathrm{~min}$ [11].

With regard to Figure 1-C by raising the device power up to $60 \%$, the amount of polyphenolics ex- traction efficiency increases and until $80 \%$ a marginally rising trend was observed and declined thereafter. Ultrasonic waves generate numerous physical and chemical reactions, by means of creation and growth of bubbles in the environment and their implosion under mechanical forces. When ultrasonic waves pass through a liquid, given a high enough ultrasonic natural Amplitude, as a result of the negative applied pressure, small bubbles are made and periodic pressures and turbulences are formed. The bubbles implode with differing intensities and give rise to physical and chemical changes, this phenomenon is called cavitation [18]. The principal mechanism of ultrasound-assisted extraction is due to the cavitation phenomenon which leads to the generation of micro bubbles and subsequently an implosion within the liquid mass. The implosion of these bubbles is often accompanied by release vast amounts of energy which is exerted on the nearby environment in the form of shear stress [19].

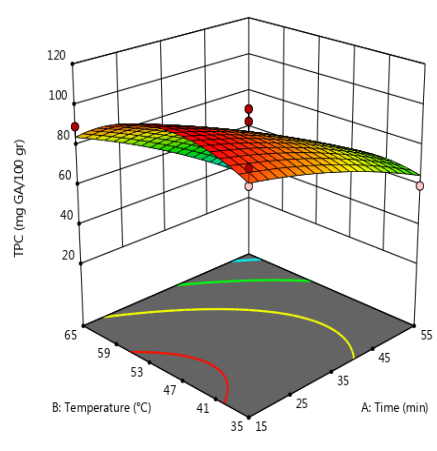

A

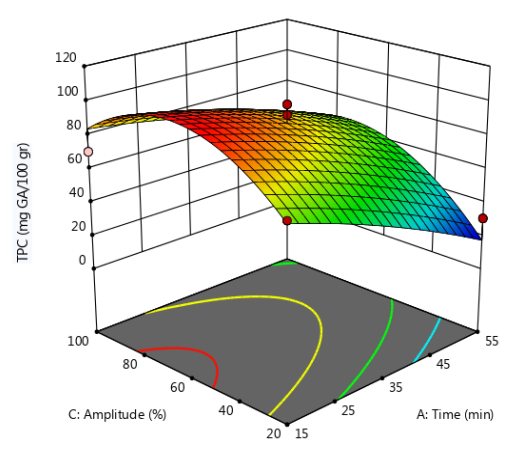

B

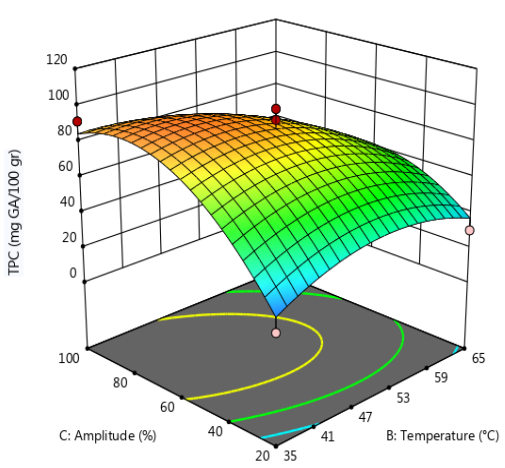

$\mathrm{C}$

Figure 1 - The effect of extraction conditions on the amount of extracted polyphenol extract from orange pomace. Note: $\mathrm{A}$ - time and temperature effects, $\mathrm{B}$ - time and amplitude effects, $\mathrm{C}$ - temperature and amplitude

Effects of process variables on antioxidant activity. Investigation of the DPPH free radical inhibition activity is one of the techniques of determining antioxidant activity. In this method, the purple color of the DPPH free radicals is neutralized and made colorless under the influence of the existent antioxidants in the extract. Thus, the degree of colorlessness of this compound is descriptive of the free radical inhibition capacity of the existent antioxidants. The results from the variance analysis demonstrate the significance of temperature, amplitude, quadratic of time and also the interaction terms of temperature and ultrasonication Amplitude and the temperature and time interaction. With regard to Eq.

Int. j. biol. chem. (Online)
5, the Amplitude was reported as to possessing the most effective parameter upon the scavenging of free radicals.

$$
\begin{gathered}
\mathrm{DPPH}=36.93-0.097 \mathrm{~A}+0.366 \mathrm{~B}+0.774 \mathrm{C}+ \\
+0.029 \mathrm{AB}-0.002 \mathrm{AC}-0.014 \mathrm{BC}-0.019 \mathrm{~A}^{2}- \\
-0.0087 \mathrm{~B}^{2}-0.0021 \mathrm{C}^{2}
\end{gathered}
$$

According to the response surface diagram in Figure 2-A, by increasing the time up to 40 minutes, an increase in inhibition percentage was observed. Heidari et al. investigated the antioxidant properties of Flomidoschema parviflora [20]. These researchers reported that by means of increasing the time, the 
free-radical scavenging has risen which is because of the growth of phenolic compounds extraction with the increase in time and their inhibition effect on the free radicals. Yet, with increasing time (times greater than $46 \mathrm{~min}$ ) this trend has become very gradual and the free-radical scavenging amount declines, with which study, the results from the relation by increasing time to $36 \mathrm{~min}$, agree.

Taking into consideration the response surface diagram related to the inhibition percentage, which is represented in Figure 2-B, the extraction temperature parameter has caused a rise in the capacity with a further increase in temperature. In the research on grape peels conducted by Ghafoor in order to optimize the conditions of ultrasound-assisted extraction, by means of the two extraction temperature and ultrasonication amplitude parameters, it was determined that with rises in the extraction temperature and ultrasonication amplitude the free-radical scavenging capacity increases [21].
According to Figure 2-C related to the free-radical inhibition effect, the amplitude parameter, originally increased the capacity of up to $80 \%$, and then led to its decrease. The reason behind the aforementioned results can be described as the rise in amplitude, by means of cavitation, brings about the breakage of the plant cell membrane and further solvent penetration into the inside of the plant cell, as well as improving the mass transfer and the contact surface between the solid and liquid phases, through membrane decomposition and its release and fast spread into the liquid phase. In the research carried out by Ahmadian and Niazmand, the results showed that with an increase in the amplitude, the free-radical scavenging amount has grown, in such a way that at $100 \%$ of amplitude, the highest inhibition percentage was observed [16]. In fact, this is a result of the higher polyphenolic compounds extraction at this amplitude and therefore increasing cell wall destruction and expanded exit and access of such materials.



A

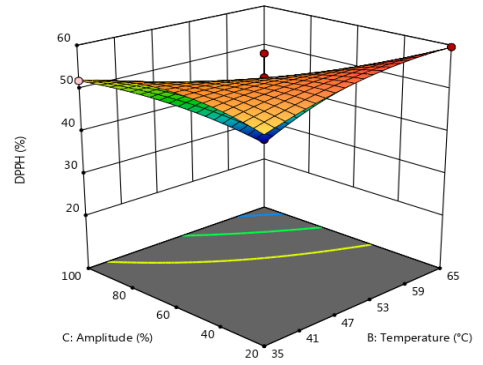

B



C

Figure 2 - The effects of the extraction conditions on the free-radical scavenging percentage of the extracted orange pomace extract. Note: $\mathrm{A}$ - the effects of temperature and time. $\mathrm{B}$ - the effects of temperature and amplitude. $\mathrm{C}$ - the effect of time and amplitude

Effects of process variables on extraction yield. Examination of the variance analysis table (Table 3) and Eq. 6 shows that the time, amplitude and quadratic of amplitude have the stronger effect on the amount of extraction efficiency.

$$
\begin{gathered}
\text { YELD }=3.56+0.09 \mathrm{~A}+0.01 \mathrm{~B}+0.19 \mathrm{C}+ \\
+0.002 \mathrm{AB}+0.00036 \mathrm{AC}-0.0014 \mathrm{BC}-0.0029 \mathrm{~A}^{2}- \\
-0.00048 \mathrm{~B}^{2}-0.0013 \mathrm{C}^{2}
\end{gathered}
$$

With regard to the extraction efficiency response surface diagram displayed in Figure 3-A, with an increase in time up to $46 \mathrm{~min}$, growth in the efficiency amount was observed. Time increases the mass transfer period. The drop in the effective constituent extraction amount with an increase in time from 43 to $55 \mathrm{~min}$ is probably caused by the destruction of some active natural compounds. One can describe that the longer time period, having brought about the enhanced cell wall disruption, leads to the extraction of insoluble compounds within the solvent, which results in the lower solvent penetration of cells [22; 23].

Furthermore, bearing in mind the significance of the temperature parameter, it is validated that with an increase in the extraction temperature, the extraction efficiency amount is expanded. Temperature is one of the key factors in the extraction efficiency 
amount, in a way that the rise in temperature has caused an increase in the solvent penetration rate (Figure 3-B).

According to the response surface diagram, with an increase in the device output up to $76 \%$, an enhancement in extraction efficiency amount was observed (Figure 3-C). The extraction amount growth by an increase in Amplitude is probably because of the cavitation phenomenon resultant of the ultrasonication; the cavitation phenomenon leads to increased plant tissue [24]. The decline in the effective constituents' extraction amount, caused by increasing the ultrasonication amplitude from $80 \%$ to $100 \%$, is probably a result of the destruction of some active natural compounds because of the high amplitude of the waves [24].

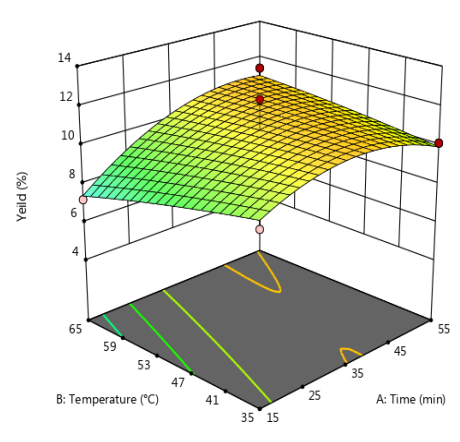

A

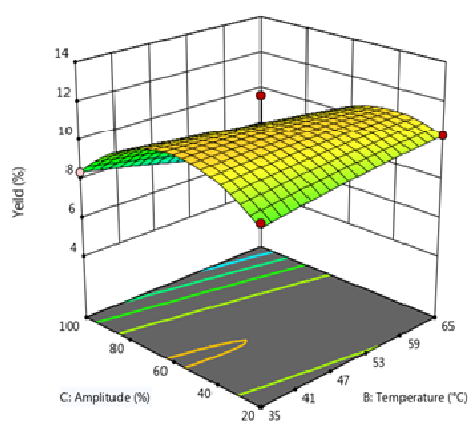

Figure 3-B

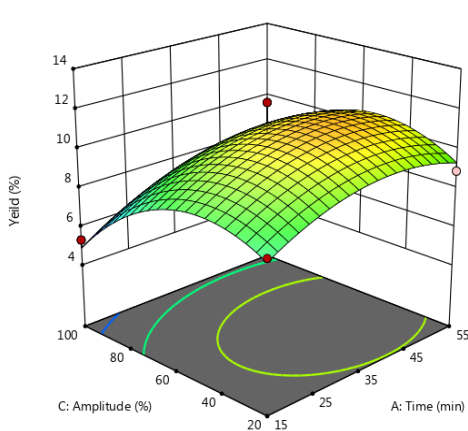

Figure 3-C

Figure 3 - The effects of the extraction conditions on the extraction yield of the extracted orange pomace extract. Note: A - the effects of temperature and time; $\mathrm{B}$ - the effects of temperature and amplitude; $\mathrm{C}$ - the effect of time and amplitude

Optimization comparison ultrasound-assisted extraction with conventional extraction. The measurement of total phenolic compounds, freeradical scavenging, and extraction efficiency amount through maceration and ultrasonication methods demonstrated the method of extraction has a profound effect on the total amount of phenolic compounds in terms of gallic acid. As apparent, the ultrasonication method has extracted more phenolic compounds compared to the maceration method (for the ultrasonication method, the phenolic compounds amount in terms of gallic acid was obtained as 91.96 $\mathrm{mg}$, the free-radical scavenging amount as $57.89 \%$ and the extraction efficiency as $10.62 \%$ and for the maceration method the phenolic compounds amount was obtained as $11.10 \mathrm{mg}$ of gallic acid, the free-radical scavenging as $2.79 \%$ and the extraction efficiency as $4.46 \%$ per $5 \mathrm{~g}$ of the initial powder). It can be said the shear stress exerted by ultrasonic waves lead to the breakdown of large polymer molecules, which in turn results in the better extraction of phenolic compounds compared to the maceration method. These results are in accordance with the report by Albu et al., who reported that utilization of the ultrasonication method led to additional extraction of carnosic acid from rosemary [26].

Int. j. biol. chem. (Online)
Findings related to the corrosion activity of free radicals in the different extraction methods, i.e. ultrasonication and maceration, is indicative of the notable difference between methods [20]. The extract produced from the ultrasonication method possesses obtains higher free-radical corrosive activity than that of the maceration method and one can state that the enhanced phenolic compounds extraction in the ultrasonication method, in comparison to the maceration method, has led to the increased antioxidantal activity in the ultrasonication method.

\section{Conclusion}

Orange pomace has agreeable antioxidant activity due to high amounts of polyphenolic compounds. With regard to the rich vegetation of the country in terms of the area under cultivation and production of orange fruits, considering its nutritional and pharmaceutical rating, it is possible to have it introduced as a natural antioxidant source within the food industry. Analysis of the Box-Behnken design response surface with three independent variables consisting of time, temperature and device ultrasonication amplitude serving as effective parameters on the extraction of antimicrobial compounds from orange

International Journal of Biology and Chemistry 12, № 2, 10 (2019) 
pomace was carried out. The finding signaled that the response surface methodology can be used satisfactorily in the evaluation of the efficiency of the extraction procedure employed. All three ultrasonication extraction parameters: temperature, time and amplitude led to the increased antioxidant activity. Suggested models have high $\mathrm{R}^{2}$ and $\mathrm{R}^{2}$ (adj.) values with insignificant lack of fit value and low coefficient of variations showing their suitability in predicting the evaluated parameters. On the one hand, by utilizing the models, adjustment of the extraction conditions is made possible, and on the other, considering the utilized extraction conditions, predict and rectify the desired properties.

\section{Acknowledgment}

Financial support was provided by the Agricultural Engineering Research Department, Khorasan Razavi Agricultural and Natural Research and Education, AREEO Mashhad, Iran.

\section{References}

1. Sagdic O., Ozturk I., Kisi O. (2012) Expert systems with applications. Modeling antimicrobial effect of different grape pomace and extracts on $S$. aureus and E. coli in vegetable soup using artificial neural network and fuzzy logic system. no. 39, pp. 6792-6798.

2. Martin J., Porto E., Correa C., Alencar M., Gloria E., Cabral I., Aquino L. (2012) Antimicrobial potential and chemical composition of agro-industrial wastes. J Nat Prod., no. 5, pp. 27-36.

3. Adamez J., Samino E.G., Sanchez E.V., Gomez D.G. (2012) In vitro estimation of the antibacterial activity and antioxidant capacity of aqueous extracts from grape-seeds (Vitis vinifera L.). Food Control, no. 24, pp. 136-141.

4. Liu S., Yang F., Zhang C., Ji H., Hong P., Deng C. (2009) Optimization of process parameters for supercritical carbon dioxide extraction of Passiflora seed oil by response surface methodology. $J \mathrm{Su}$ percrit Fluid., no. 48, pp. 9-14.

5. Corrales M., Garcia A., Butz P., Tauscher B. (2009) Extraction of anthocyanins from grape skins assisted by high hydrostatic pressure. J Food Eng., no. 90 , pp. $415-421$.

6. Pompeu D., Silva E, Rogez H. (2009) Optimisation of the solvent extraction of phenolic antioxidants from fruits of Euterpe oleracea using response surface methodology. Biores Technol., no. 100, pp. 6076-6082.

Int. j. biol. chem. (Online)
7. Wijngaard H., Hossain M.B, Rai D.K., Brunton N. (2012) Techniques to extract bioactive compounds from food by-products of plant origin. Food Res Int., no. 46, pp. 505-513.

8. Sharayei P., Azarpazhouh A. Investigating the effect of ultrasound on antioxidant and antifungal properties of pomegranate peel. Agricultural and Natural Resources Research and Education Center, AREEO, Mashhad, Iran. 2017.

9. Jimenez A., Beltran G. (2007) Ultrasonics sonochemistry. High-power ultrasound in olive paste pretreatment. Effect on process yield and virgin olive oil characteristics. vol. 6, no. 14, pp. 725-731.

10. Porto C.D., Porretto E., Decorti D. (2013). Comparison of ultrasound-assisted extraction with conventional extraction methods of oil and polyphenols from grape (Vitis vinifera L.) seeds. Ultrasonics Sonochem., no. 20, pp. 1076-1080.

11. Wang J., Sun B., Cao Y., Tian Y., Li X. (2008) Optimization of ultrasound-assisted extraction of phenolic compounds from wheat bran. Food Chem., vol. 2, no. 106, 804-810.

12. Von Gadow A., Joubert E., Hansmann C.F. (1997) Comparison of the antioxidant activity of aspalathin with that of other plant phenols of rooibos tea (Aspalathus linearis), $\alpha$-tocopherol, BHT, and BHA. J Agric Food Chem., vol. 3, no. 45, 632-638.

13. Silva E., Rogez H., Larondelle Y. (2007) Optimization of extraction of phenolics from Inga edulis leaves using response surface methodology. Sep Purif Technol., vol. 3, no. 55, pp. 381-387.

14. Wissam Z., Ghada B., Wassim A., Warid K. (2012) Effective extraction of polyphenols and proanthocyanidins from pomegranate's peel. Int $J$ Pharm Sci., vol. 3, no. 4, pp. 675-682.

15. Negro C., Tommasi L., Miceli A. (2003) Phenolic compounds and antioxidant activity from red grape marce extracts. Bioresource Technol., no. 87, pp. 41-44.

16. Ahmadian Koochaksarayee Z., Niazmand R. (2016) Optimization of extraction of effective compounds from saffron petals by ultrasound-assay method. Novel Food Tech., no. 13, pp. 121-135.

17. Chan S., Lee C., Yap C., Mustapha W.A.W., Ho C. (2009) Optimization of extraction conditions for phenolic compounds from limau purut (Citrus hystrix) peels. Int Food Res. J., vol.2, no. 16, pp. 203-213.

18. Chemat F., Zill-e-Huma, and Khan M.K. (2011) Applications of ultrasound in food technology: processing, preservation and extraction. Ultrason Sonochem., vol. 4, no. 18, pp. 813-835.

International Journal of Biology and Chemistry 12, № 2, 10 (2019) 
19. Ji J., Lu X., Cai M., Xu Z. (2006) Ultrasonics sonochemistry. Improvement of leaching process of Geniposide with ultrasound. vol. 5, no. 13, pp. 455462.

20. Heydari Majd M., Mortazavi A., Asili J., Bolouriyan Sh. (2012) Herbal medicine. optimization of extraction of phenolic compounds from Flomidoschema parviflora by ultrasound-assay method, no 1 , pp. 7-13.

21. Ghafoor K., Choi Y., Yeong Jeon, Ju and Hee Jo (2009) Optimization of ultrasound-assisted extraction of phenolic compounds, antioxidants, and anthocyanins from grape (Vitis vinifera) seeds. Agric Food Chem., vol. 11, no. 57, pp. 4988-4994.

22. Rosangela J., Lisiane F., Valeria P., Claudio D., Ana Paula O., Jose O. (2007) Ultrasonics sonochemistry. The use of ultrasound in the extraction of Ilex paraguariensis leaves: a comparison with maceration. no. 14, pp. 6-12.
23. Tian Y., Xu Z., Zheng B., and Lo Y.M. (2013) Optimization of ultrasonic-assisted extraction of pomegranate (Punica granatum L.) seed oil. Ultrasonics Sonochem., no. 20, pp. 202-208.

24. Vilkhu K., Mawson R., Simons L., Bates D. (2008) Applications and opportunities for ultrasound assisted extraction in the food industry - a review. Innov Food Sci Emerg Technol., vol. 2, no. 9, pp. 161-169.

25. Lianfu Z., Zelong L. (2008) Ultrasonics sonochemistry. Optimization and comparison of ultrasound/microwave assisted extraction (UMAE) and ultrasonic assisted extraction (UAE) of lycopene from tomatoes. vol. 5, no. 15, pp. 731-737.

26. Albu S., Joyce E., Paniwnyk L., Lorimer J., Mason T. (2004) Potential for the use of ultrasound in the extraction of antioxidants from Rosmarinus officinalis for the food and pharmaceutical industry. Ultrason Sonochem., vol. 3, no. 11, pp. 261-265. 